\title{
International
}

\section{Inaugural MENA Workshop Held}

\author{
"STATES IN TRANSITION, CON- \\ STITUTIONAL ENGINEERING AND \\ POLITICAL SCIENCE RESEARCH"
}

APSA's inaugural Middle East and North Africa (MENA) Workshop was conducted February 9-14 in partnership with the American University in Cairo (AUC) in Cairo, Egypt. The event is part of a multiyear initiative to support political science research and networking in the Arab Middle East and North Africa through a series of residential political science workshops at regional universities and research institutions. Funded by the Carnegie Corporation of New York, the MENA Workshops program is a major component of APSA's efforts to engage with political science communities outside the United States and support research networks linking US scholars with their colleagues overseas.

The February workshop was led by a team of four faculty from the United States and Egypt, and attended by 16 political and social scientists. The participants, who included 12 scholars from the region and 4 from Europe, were competitively selected from a pool of more than 60 applicants.

Titled "States in Transition, Constitutional Engineering and Political Science Research," the workshop focused on conceptualizations of democracy/democratization and how these concepts are measured, studied, and analyzed in political science

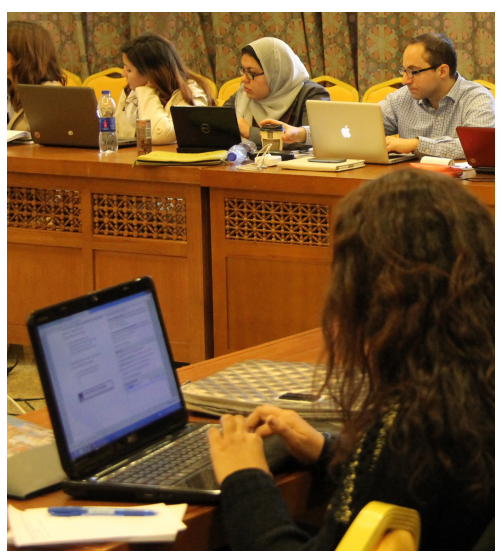

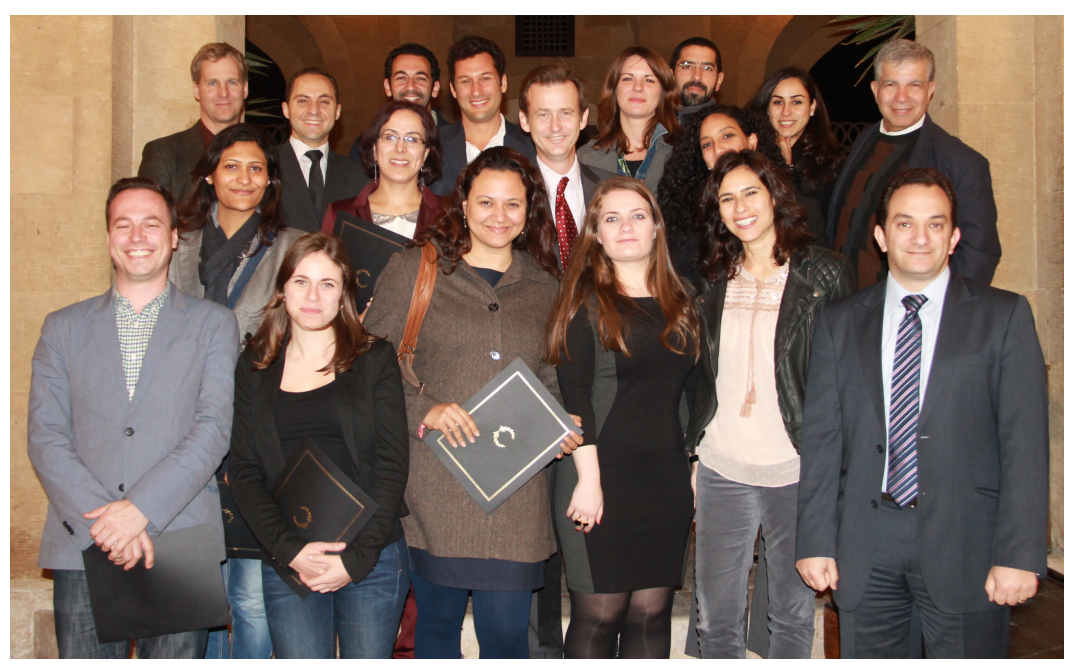

Participants in the MENA workshop, held in Cairo. Back row: John Huber, Abdul-Wahab Kayyali, Ahmed Morsy, Guy Burton, Sarah Wessel, Karim Sadek, Dima Smaira, and Bahgat Korany: Middle Row: Wafaa Dawoud, Ilham Sadoqi, Nolan McCarty, and Mona Farag; Front Row: Lucas Leemann, Tereza Jermanova, Nesreen El Molla, Jinan Al-Habbal, Nadine Sika, and Chadi Abou Daher.

research. Participants drew on an extensive set of readings as well as their own research to discuss democracy and democratic changes in the Middle East. A public panel presentation sponsored by the AUC Forum provided an opportunity for participants to discuss these themes with members of the campus community. Afternoon sessions were devoted to specialized training in quantitative methods and in-depth introduction to the statistical analysis software Stata. Participants also made time to visit the Pyramids of Giza and enjoy Al-Azhar Park.

For the next several months, participants will develop discrete research projects for presentation and peer review at a follow-up workshop in June 2014. The June session will extend the discussion on democracy and quantitative methods with particular focus on economic development from both a comparative political economy and international political economy approach. Following this, participants will receive three years' complimentary APSA membership and will be eligible to apply for small grants to support their further research.

Participants work on STATA during the MENA Workshop in Cairo, February 2014. Photo by Andrew Stinson.

\section{Workshop Co-Leaders}

Mr. John Huber, Columbia University, USA

Mr. Bahgat Korany, American University in Cairo, Egypt

Mr. Nolan McCarty, Princeton University, USA

Ms. Nadine Sika, American University in Cairo, Egypt

\section{Workshop Participants}

Mr. Chadi Abou Daher, Lebanese American University, Lebanon

Ms. Jinan Al-Habbal, St. Andrews University, United Kingdom

Ms. Nermin Allam, University of Alberta, Canada

Mr. Guy Burton, University of Nottingham, Malaysia

Ms. May Darwich, Edinburgh University, United Kingdom

Ms. Wafaa Dawoud, Beni Suef University, Egypt

Ms. Nesreen El Molla, Cairo University, Egypt

Ms. Mona Farag, University of Exeter, United Kingdom

Ms. Tereza Jermanova, University of Exeter, United Kingdom

Mr. Abdul-Wahab Kayyali, George Washington University, USA

Mr. Lucas Leemann, Columbia University, USA 
Mr. Karim Sadek. American University in Beirut, Lebanon

Ms. Ilham Sadoqi. Mohammed V University-Souissi, Morocco

Ms. Dima Smaira, Durham University, United Kingdom

Ms. Yossra Taha, Cairo University, Egypt

Ms. Sarah Wessel, University of Hamburg, Germany

For more information on the 2014 workshop or the overall program, please visit APSA's MENA Workshops www.apsa.org/ menaworkshops.

\section{MENA Workshop}

THEME SELECTED: "CONTINUITY AND TRANSFORMATION: EXPLAINING CROSS NATIONAL VARIATION IN THE EARLY STAGES OF THE ARAB SPRING MOVEMENTS"

APSA's Middle East and North Africa (MENA) Project Steering Committee is pleased to announce that the next 2014 MENA Workshop series will kick off with a one-week program in Amman, Jordan from May 11-16. A follow-up workshop will be held at Lebanese American University in September. Leading this program will be Denise DeGarmo (Southern Illinois University, Edwardsville; USA), Lourdes Habash (Birzeit University, Palestine), Fred H. Lawson (Mills College, USA), and Ghada alMadbouh (Birzeit University, Palestine).

A call for participant applications was issued in late January. Following a competitive selection process, up to 24 qualified applicants (20 scholars from Middle East and North African countries and four US and/or European doctoral students) will be invited to participate. The workshop aims to explore the dynamics of regime change, using the case studies of the Arab Spring as a topical empirical basis for this exploration. Workshop fellows will use a cross national perspective to analyze challenges to old regimes during the early stages of the Arab Spring movements. A program of discussion-based lectures will survey current theoretical and methodological approaches to studying the Middle East, focusing on factors such as social movements, military and domestic security forces, economic conditions, and use of social media. Additional sessions will allow participants to evaluate their current research questions and pro- vide feedback regarding research design and implementation.

The APSA MENA Workshops are supported by a grant from the Carnegie Corporation of New York. The inaugural workshop was held in Cairo, Egypt in February 2014. Focusing on early career scholars from the Arab Middle East and North Africa, the workshop program aims to enhance the capacities and resources of political scientists in the Arab MENA region, while also provide a forum for supporting their ongoing research. To learn more about the 2014 workshop or for further information on the MENA Workshop program, please visit the project website at http:// apsanet.org/menaworkshops.

\section{Africa Workshop}

\section{THEME SELECTED: "DISTRIBUTIVE GOODS AND DISTRIBUTIVE \\ POLITICS"}

After a competitive application process, the APSA Africa Project Steering Committee is pleased to announce that the 7 th annual Africa Workshop will take place from June 30 to July 11 in Maputo, Mozambique, hosted by the Higher Institute of Public Administration (ISAP). The US-based workshop leaders are Anne Pitcher and Brian Min (both University of Michigan). Their Africa-based colleagues are Rod Alence (University of Witwatersrand, South Africa), Sylvia Croese (Stellenbosch University, South Africa), and Carlos Shenga (ISAP, Mozambique).

A call for participant applications was issued in late January. Following a competitive selection process, up to 26 qualified applicants ( 22 scholars from Africa and four North American doctoral students) will be invited to participate. During the workshop, discussion will focus on the theme of distributive politics - the study of how governments allocate goods and services and how these allocations affect political outcomes. The course will combine discussion of classic and contemporary theoretical and methodological research on goods provision with hands-on statistical training in the use of $\mathrm{R}$, a publicly available statistical package. Fellows will work with a range of datasets and strengthen their ability to analyze the distribution of public and private goods and their political impacts. In addition to the substantive elements of the course, students will have opportunities to share their work and to receive comments on their research projects.

The APSA Africa Workshops are supported by a grant from the Andrew W. Mellon Foundation. The inaugural workshop was held in Dakar, Senegal at the West African Research Center in 2008. Subsequent workshops have been held in Accra, Dar es Salaam, Nairobi, Gaborone, and Ouagadougou. Focusing on early career scholars working in sub-Saharan Africa, the workshop program aims to enhance the capacities of African political scientists and build lasting networks between African scholars and their colleagues in North America.

To learn more about the 2014 workshop or for information on previous workshops visit the project website at http://www.apsanet. org/ africaworkshops/.

\section{Alumni Networking Grant Awards}

In November 2013, APSA awarded five Alumni Networking Grants to 10 Africa workshop alumni, totaling over \$35,0oo. Recipients included Richard Asante, '11 (Professional Development Grant); Rasel Madaha, '10 (Professional Development Grant); Carl LeVan, '11 and Joseph Fashagba, '11 (Publication Grant); Danielle Carter, '12, Lauren MacLean, '12, and Mesharch Katusiimeh, '12 (Workshop Grant); Bonnie Ayodele, '10, Azeez Olayian, '12, and Taiwo Owoeye, '13 (Workshop Grant).

APSA's Alumni Networking Grants are available primarily for Africa Workshops alumni. With support from the Andrew W. Mellon Foundation, over $\$ 40,000$ is available each year to support their participation in professional development opportunities, facilitate networking potential, and encourage collaboration among scholars and academic institutions across Africa. Applications are now being accepted for three types of grants: professional development grants, workshop grants, and publication grants. Application and program information can be found on the Africa Workshop website at htpp:community.apsanet.org/Africa/AlumniGrants. Questions should be directed to Andrew Stinson at africaworkshops@ apsanet.org. 